УДК 635.64:581.19

\title{
ЛИКОПИН И
}

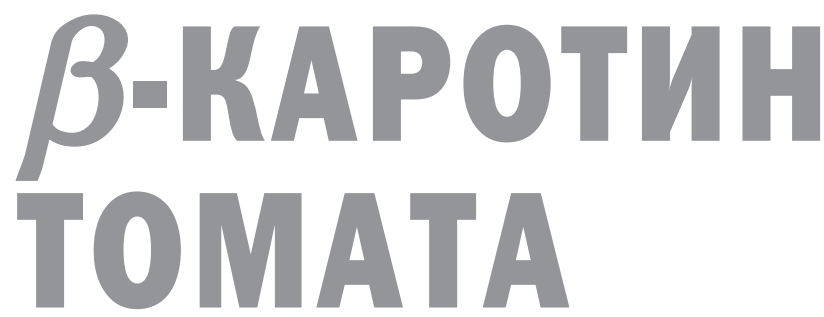

Кондратьева И.Ю. - ведущий научный сотрудник, кандидат сельскохозяйственных наук;

Голубкина Н.А. - главный научный сотрудник, доктор сельскохозяйственных наук

ФГБНУ «Всероссийский научно-исследовательский институт селекции

и семеноводства овощных культур» (ФГБНУ ВНИИССОК)

143080, Россия, Московская обл., Одинцовский р-н, п. ВНИИССОК, ул. Селекционная, д.14

E-mail:vniissok@mail.ru,segolubkina45@gmail.com

Высокая антиоксидантная активность плодов томата обусловлена не только значительным содержанием витамина С и полифенолов, но также и жирорастворимых антиоксидантов каротиноидов. Ликопин и $\beta$-каротин составляют важнейшие жирорастворимые антиоксиданты томатов, употребление которых оказывает моцное положительное действие на человеческий организм. Известно, что плоды томата являются основным источником ликопина для человека, обеспечивая до $85 \%$ всего ликопина, поступающего с пищей. Создание новых сортов томата с повышенным содержанием каротиноидов является приоритетной задачей селекционеров. В нашем исследовании установлено содержание $\beta$-каротина и ликопина у 18 сортообразцов красных, розовых, желтых и оранжевых томатов селекции лаборатории пасленовых культур ВНИИССОК. Растения вырачивали в открытом грунте на экспериментальных полях ВНИИССОК в Одинцовском районе Московской области. Выявлено характерное соотношение содержания ликопина/ $\beta$-каротина для розовых и красных плодов: от 1,5 до 10,25 и для желтых и оранжевых сортов: от 0 до 0,63. Максимальное соотношение у красных сортообразцов было характерно для линии 230-16. Наибольиие уровни ликопина у красных сортов были установлены для итамбовых линий 198-16 и $86 F_{1}$ (11,5 и 8,7 ме/100 г соответственно). У желтых сортов максимальное содержание $\beta$-каротина выявлено для линии 53-16 F, (4,1 мг/100 г), у оранжевых - у линии 184-16 (6,2 мг/100 2). Все изученные образцы томата с оранжевыми плодами имели содержание $\beta$-каротина выше, чем в стандартном образце, и довольно высокое содержание ликопина для данной группы, что свидетельствует о высокой пищевой ценности данного продукта. Сбалансированное содержание ликопина и $\beta$-каротина и низкий показатель кислотности в плодах с розовыми и желто-оранжевыми плодами делают плоды таких сортов наиболее ценными для питания детей и диетического питания людей с проблемами заболевания пищевариmельной системь.

Ключевые слова: томаты, ликопин, $\beta$-каротин, антиоксиданты.

$\mathrm{C}^{\prime}$ реди овощных культур томат занимает первое место по популярности в развитых странах и частоте применения. Высокая антиоксидантная активность плодов томата обусловлена не только значительным содержанием витамина С и полифенолов, но также и жирорастворимых антиоксидантов - каротиноидов [1]. Наиболее распространенными каротиноидами красных сортов томата являются ликопин и $\beta$-каротин, а в оранжевых и желтых сортах могут присутствовать также лютеин, Ц-каротин, нейроспорин и др. Показано, что красные плоды томата являются основным источником ликопина для человека, обеспечивая до 85\% всего ликопина, поступающего с пищей [5]. Являясь ациклическим аналогом $\beta$-каротина, ликопин, в отличие от $\beta$ каротина, не обладает про-А-витаминной активностью, однако, антиоксидантная активность этого соединения вдвое выше, чем у $\beta$-каротина и в 10 раз выше, чем у витамина E [6]. Чрезвычайно важным представляется также факт улучшения усвоения ликопина организмом человека при совместном приеме с $\beta$-каротином [7], что предполагает целесообразность предпочтения использования плодов томата перед биологически активными добавками к пище. Другим важным показателем предпочтительного использо- 


\section{PLANTS PHYSIOLOGY AND BIOCHEMISTRY}

вания природных источников ликопина перед синтетическими препаратами и БАДами является установление удивительного факта отсутствия защитного действия в отношении рака предстательной железы при приеме чистого ликопина, выделенного из плодов томата, и наличие мощной защиты при потреблении тех же плодов в дозах, соответствующих равному количеству ликопина [8]. Крупномасштабные эпидемиологические исследования выявили существование обратной корреляции между уровнем потребления томатов и продуктов из них (соусы, кетчупы, паста и т.п.) и риском возникновения и развития различных форм рака (предстательной железы, желудочно-кишечного тракта и др.) $[8,9]$. Важную роль играет потребление плодов томата и в защите организма от сердечно-сосудистых заболеваний [10]. Создание новых сортов томата с повышенным содержанием каротиноидов, таким образом, является приоритетной задачей селекционеров.

Целью настоящего исследования было проведение оценки содержания $\beta$-каротина и ликопина в красных, розовых, желтых и оранжевых плодах сортов томата селекции лаборатории пасленовых культур ВНИИССОК.

\section{Материалы и методика}

Работа выполнена в лаборатории селекции и семеноводства пасленовых культур ВНИИССОК. Растения выращивали в открытом грунте на экспериментальных полях ВНИИССОК в Одинцовском районе Московской области. Почва дерново-подзолистая тяжелосуглинистая, pH 6-8, содержание гумуса - 2,05\%, $\mathrm{P}_{2} \mathrm{O}_{5}-450$ мг/кг, $\mathrm{K}_{2} \mathrm{O}-357$ мг/кг, щелочно-гидролизуемый азот - 108 мг/кг почвы, сумма обменных оснований - 95.2\%. Агротехника стандартная для культуры томата. Посев на рассаду для открытого грунта производили 25 апреля в кассеты (ячейка 5х5 см), начало всходов наблюдали 5 мая, массовые всходы 7 мая. Высадку в открытый грунт осуществляли 29-30 мая. Схема посадки двухстрочная 70х50×35 см. Начало созревания (10\% созревших плодов) - 15 августа. Закладку полевых опытов, фенологические наблюдения, учет урожая, описание морфологических признаков проводили согласно Методическим указаниям по селекции сортов и гибридов томата для открытого и защищенного грунта.

Содержание каротиноидов устанавливали спектрофотометрически после хроматографического разделения ликопина и $\beta$-каротина на хроматографической бумаге Ватман ЗА в гексане, измеряя величину поглощения экстракта при 450 нм (бета-каротин) и 474 нм (ликопин) [2].

Статистическую обработку результатов осуществляли с использованием статистической программы Excel.

\section{Результаты исследования и их обсуждение}

В лаборатории пасленовых культур ВНИИССОК созданы новые сорта томата для открытого грунта с высоким содер-
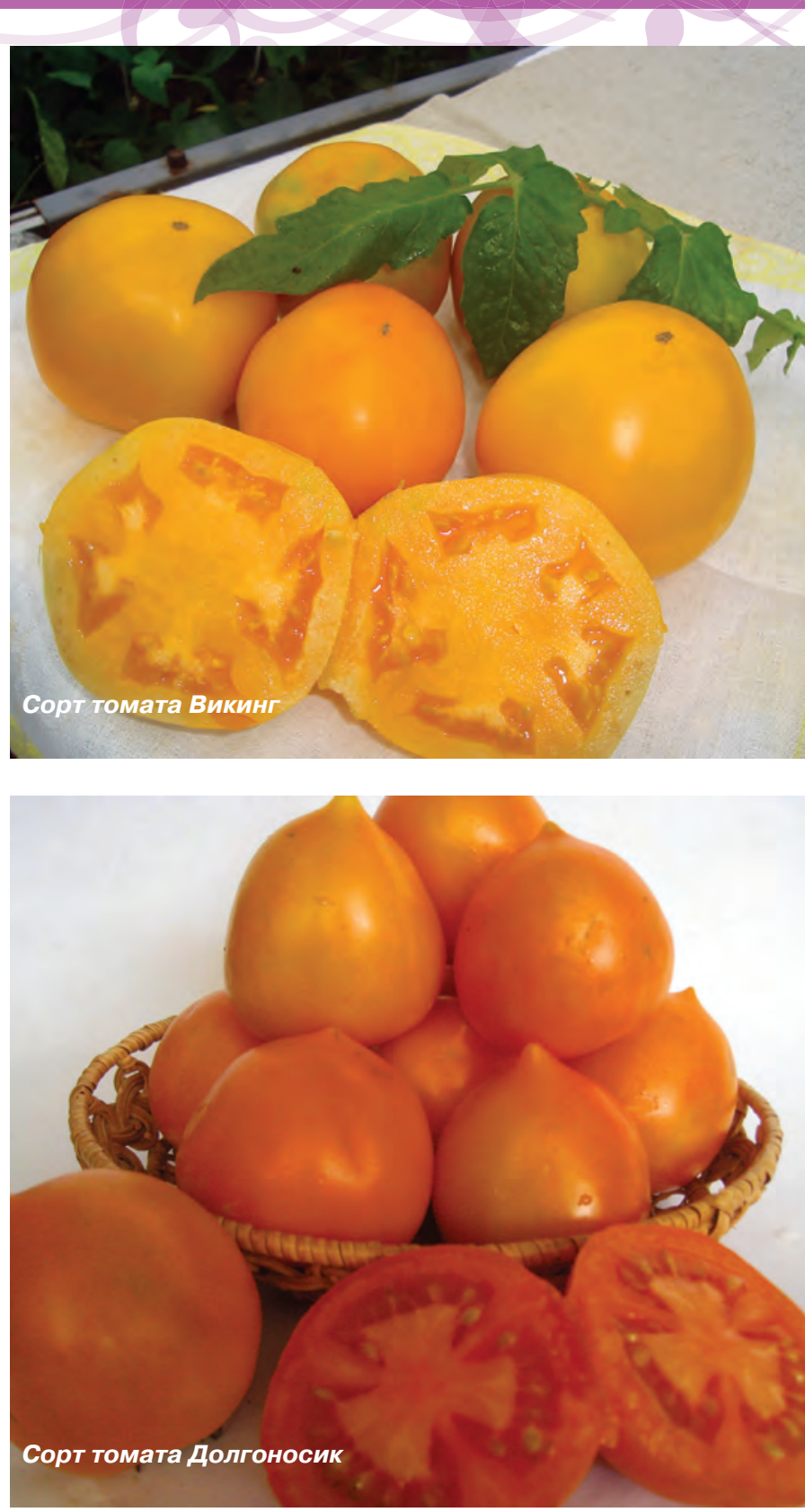

жанием ликопина (Магнат, Гном, Дубок, Челнок, Северянка и др), $\beta$-каротина (Росинка, Викинг, Долгоносик), а также со сбалансированным содержанием ликопина и $\beta$-каротина с розовыми и малиновыми плодами (Малинка, Лотос, Содружество) $[3,4]$.

Изучение групп селекционных линий томата по комплексу хозяйственно ценных признаков, а также содержания в них ликопина и $\beta$-каротина позволило установить следующее (табл. 1).

Наибольшее содержание ликопина оказалось характерным для штамбовых линий 198-16 и 164-16 (11,5 и 6,6 мг/100 г соответственно). Линия 198-16 отличалась значительным содержанием $\beta$-каротина и сухого вещества в плодах (до 7\%). В образцах с обыкновенным типом растения две линии 230-16 и 86-16 имели 8,2 и 8,7 мг/100 г ликопина соответственно. Эти линии среднего и раннего срока созревания.

При изучении по комплексу хозяйственных признаков и содержанию $\beta$-каротина в образцах с желтыми плодами все 


\section{1. Содержание ликопина и $\beta$-каротина в перспективных сортах томатов}

\begin{tabular}{|c|c|c|c|c|c|}
\hline Линия & $\begin{array}{l}\text { Тип куста, } \\
\text { окраска } \\
\text { плода }\end{array}$ & $\begin{array}{c}\text { Число суток } \\
\text { от всходов } \\
\text { до } \\
\text { созревания } \\
\end{array}$ & $\begin{array}{c}\text { Содержание } \\
\text { ликопина, } \\
\text { мг/100 г }\end{array}$ & $\begin{array}{c}\text { Содержание } \\
\beta \text {-каротина, } \\
\text { мг/100 г }\end{array}$ & $\begin{array}{c}\text { Соотношение } \\
\text { уровней } \\
\text { ликопин/ } \\
\beta \text {-каротин }\end{array}$ \\
\hline \multicolumn{6}{|c|}{ Желтые } \\
\hline (53) F1 (Л-08-14 x Лотос) & Обыкновенный, насыщенно желтый & $100-105$ & $2,6 a$ & $4,1 \mathrm{a}$ & 0,63 \\
\hline (45) F1 (Л.Желтая x Росинка) & Обыкновенный, насыщенно желтый & $100-105$ & $1,2 b$ & $2,5 b$ & 0,48 \\
\hline Линия Викинг & Обыкновенный, желтый & $110-112$ & $0,31 \mathrm{c}$ & $1,15 \mathrm{c}$ & 0,27 \\
\hline Стандарт Круглый желтый 2 & Обыкновенный, бледно- желтый & $110-112$ & $0,12 d$ & $0,77 d$ & 0,16 \\
\hline \multicolumn{6}{|c|}{ Оранжевые } \\
\hline \multicolumn{6}{|l|}{ (175) $F_{5}$} \\
\hline (Росинка х Чаровница) & Штамбовая & $102-107$ & $1,2 \mathrm{a}$ & $3,4 a$ & 0,4 \\
\hline (184) линия Долгоносик -крупноплодная & П/штамбовая & $101-107$ & $2,2 b$ & $6,2 \mathrm{~b}$ & 0,35 \\
\hline Стандартный Апельсиновый & Обыкновенный & $111-116$ & $0,31 \mathrm{c}$ & $3,15 c$ & 0,1 \\
\hline (168) F5 (Чародей x оранжевый) & Обыкновенный & $100-108$ & 0 & $3,6 a$ & 0 \\
\hline \multicolumn{3}{|l|}{ Среднее } & $0,99 \pm 0,81$ & $3,11 \pm 2,3$ & $0,30 \pm 0,17$ \\
\hline \multicolumn{3}{|l|}{ Интервал значений } & $0-2,6$ & $0,77-6,2$ & $0-0,63$ \\
\hline \multicolumn{3}{|c|}{ CV } & $81,8 \%$ & $39,5 \%$ & $56,7 \%$ \\
\hline \multicolumn{6}{|c|}{ Красные } \\
\hline \multicolumn{6}{|l|}{ (230) Линия } \\
\hline (Чаролей x Мутант-2) & Обыкновенный & $98-103$ & $8,2 a$ & $0,8 \mathrm{a}$ & 10,25 \\
\hline (86) F5 (Муеант-2 х Денар) & Обыкновенный & $100-105$ & $8,7 \mathrm{~b}$ & $1,3 b$ & 6,7 \\
\hline (198) Линия (Барон х Арго) ИИ & П/штамбовый & $102-107$ & $11,5 \mathrm{c}$ & $1,8 \mathrm{c}$ & 6,4 \\
\hline (164) Линия (Первоцвет x Арго) & Штамбовый & $98-102$ & $6,3 d$ & $1,0 \mathrm{a}$ & 6,3 \\
\hline (156) Линия Реванш x 34-15 & Штамбовый & $100-105$ & $3,4 \mathrm{e}$ & $0,8 \mathrm{a}$ & 4,25 \\
\hline (163) Линия (Перст x 611/07) & Штамбовый & $103-108$ & $3,3 \mathrm{e}$ & $0,9 a$ & 3,67 \\
\hline Денар & Обыкновенный & $105-107$ & $8,03 a$ & $2,90 \mathrm{~d}$ & 2,8 \\
\hline Стандарт Грунтовый грибовский 1180 & Обыкновенный & $107-110$ & $4,76 f$ & $3,08 \mathrm{~d}$ & 1,5 \\
\hline \multicolumn{6}{|c|}{ Розовые } \\
\hline Стандарт Малиновый & Обыкновенный & $107-114$ & $9,92 \mathrm{a}$ & $1,82 \mathrm{a}$ & 5,0 \\
\hline (186) Линия (Перст x Лотос) & Обыкновенный & $105-109$ & $3,3 b$ & $0,9 b$ & 3,67 \\
\hline \multicolumn{3}{|l|}{ Среднее } & $6,74 \pm 2,53$ & $1,53 \pm 0,70$ & $5,05 \pm 1,89$ \\
\hline \multicolumn{3}{|l|}{ Интервал значений } & $3,3-11,5$ & $0,8-3,08$ & $1,5-10,25$ \\
\hline \multicolumn{3}{|c|}{ CV } & $37,5 \%$ & $45,8 \%$ & $37,4 \%$ \\
\hline
\end{tabular}

три выделенные линии отличались высоким его содержанием. В линиях 45-16 и 53-16 с плодами насыщенного желтого цвета содержание $\beta$-каротина в 3-4 раза превышало стандарт. По содержанию ликопина эти линии также имели показатели выше стандарта, особенно линия 43-16. Эти линии среднеранние.

Из перспективных линий с оранжевыми плодами высокое содержание $\beta$-каротина и ликопина отмечено у линии 18416.

Все изученные образцы томата с оранжевыми плодами имели содержание $\beta$-каротина выше, чем в стандартном образце, и довольно высокое содержание ликопина для данной группы, что свидетельствует о высокой пищевой ценности данного продукта. Сбалансированное содержание ликопина и $\beta$-каротина и низкий показатель кислотности в плодах с розовыми и желто-оранжевыми плодами делают плоды таких сортов наиболее ценными для питания детей и диетического питания людей с проблемами заболевания пищеварительной системы. У образцов с розовыми плодами содержание ликопина превышает содержание $\beta$-каротина.

В целом соотношение ликопин $/ \beta$-каротин составляет для красных и розовых сортов 1,5-10,3, в то время как аналогичный интервал соотношений для желтых и оранжевых сортов достигает всего 0-0,63. Сравнительная характеристика по содержанию ликопина и $\beta$-каротина в группах с желтыми и оранжевыми плодами показала, что содержание $\beta$-каротина в оранжевоплодных образцах в 2 раза больше, чем в образцах с желтыми плодами и в 4 раза больше по содержанию ликопина. В группе образцов с красными и розовыми плодами содержание ликопина в красноплодных образцах в 6 и 4 раз (соответственно) больше, чем каротина. При достаточно высоком содержании ликопина в образцах с розовыми плодами наблюдается высокое содержание и $\beta$-каротина. 


\section{PLANTS PHYSIOLOGY AND BIOCHEMISTRY}

В проблеме создания культурных сортов с высоким содержанием $\beta$-каротина в плодах, одной из наиболее важных задач является не столько увеличение количества бетакаротина, сколько совмещение содержания ликопина с повышенной концентрацией в них $\beta$-каротина.
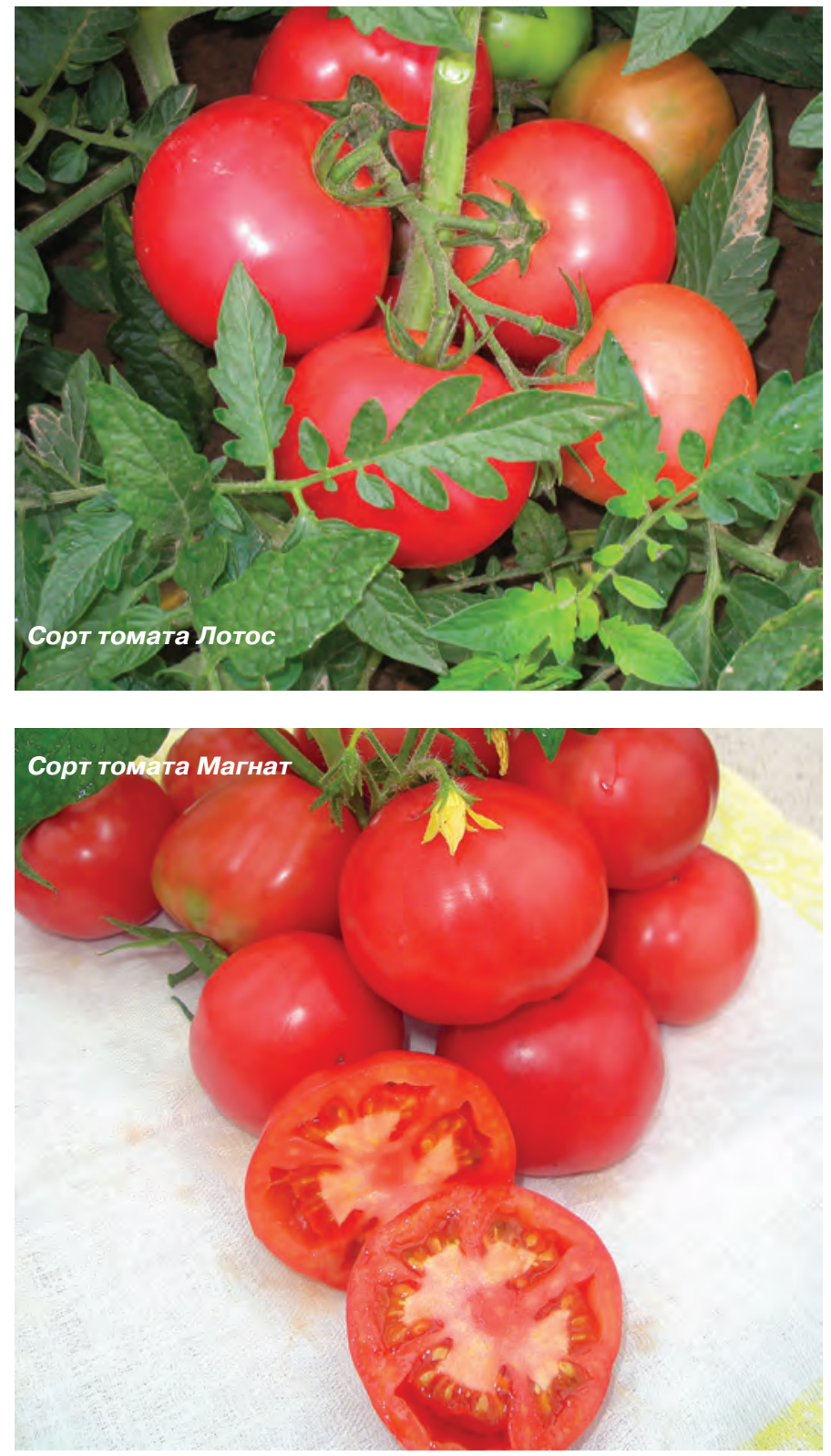

\section{Лumepamypa}

1. Голубкина Н.А., Сирота С.М., Пивоваров В.Ф., Яшин А.Я., Яшин Я.И. Биологически активные соединения овощей/ВНИИССОК. 2010.

2. Руководство по оценке качества биологически активных добавок к пище/М.Минздрав.-2004.

3. Кондратьева И.Ю. Скороспелые, холодостойкие сорта томата для открытого грунта/Москва, 2016. - 109с.

4. Пивоваров В.Ф., Скворцова Р.В., Кондратьева И.Ю. Частная селекция томата/М., ВНИИССОК. -2002.-285 с.

5. Anand P., Runnumakata A.B., Sundaram C., Harikumar K.B., Tharakan S.T., Lai O.S., Sung B., Aggarwal B.B. Cancer is preventable disease that requires major lifestyle changes//Pharm Res. 2008. Vol.25(9). P.2097-2126.

6. DiMascio P., Kaiser S., Sies H. Lycopene as the most effective biolog-

\section{LICOPENE AND B-CAROTENE IN TOMATO}

\author{
Kondratieva I.Yu., Golubkina N.A.
}

Federal State Budgetary Research Institution

'All-Russian Scientific Research Institute

of vegetable breeding and seed production'

143080, Russia, Moscow region, Odintsovo district,

p. VNIISSOK, Selectionnaya st., 14

E-mail:vniissok@mail.ru,segolubkina45@gmail.com

\section{Summary}

The high antioxidant activity in tomato fruits is caused not only by sufficient content of vitamin $\mathrm{C}$ and polyphenols but also the carotenoids and the fat soluble antioxidants. Lycopene and beta-carotene are the main fat-soluble antioxidants, the consumption of which influences positively on human's health. It is known that tomato fruits are the source of lycopene for human diet, providing up to $85 \%$ of the total lycopene in food. The breeding program for tomato cultivars with high content of carotenoids is a very important task for breeders. In our study the content of betacarotene and lycopene was assessed in 18 tomato accessions with red, pink, yellow and orange fruits obtained in Solanaceae Breeding Laboratory at VNIISSOK. All plants were grown in experimental open field in Odintsovo region, Moscow oblast, VNIISSOK. It was revealed that the typical concentration ratio of lycopene to beta-carotene for pink and red fruits was 1.5 to 10.25 , but for yellow and orange fruits was 0 to 0.63 . Highest ratio was observed in red fruits in line 230-16. The highest lycopene content was found in red fruits of tree type tomato lines 198-16 and 86F1 (11.5 and $8.7 \mathrm{~g} / 100 \mathrm{~g}$. respectively). The highest content of betacarotene was in yellow fruits of line 53-16 F1 (4.1 mg/100g) and orange fruits of line $184-16(6.2 \mathrm{mg} / 100 \mathrm{~g})$. All studied accessions with orange fruits had the higher content of beta-carotene than in standard and highest content of lycopene in this group of accessions. Thus, these fruits had the high nutritional value. The balanced content of lycopene and beta-carotene and low acidity in pink and yellow-orange tomato fruits makes these cultivars the most valuable for children's diet and people with problems of digestive system.

Key words: tomato, lycopene, beta-carotene, antioxidants

ical carotenoid singlet oxygen quencher//Arch Biochem Biophys. 1989. Vol.274. P.532-538.

7. Boileau T.W., Liao Z., Kim S., Leeshow S., Erdman J.W., Clinton S.K. Prostate carcinogenesis in $\mathrm{N}$-methyl-N-nitrosourea (NMU)-testosterone-treated rats fed tomato powder, lycopene, or energy-restricted diets//J.Nat.Cancer Inst. 2003. Vol.95. P.1578-1586.

8. Giovannucci E. Tomatoes, tomato-based products, lycopene, and cancer: review of the epidemiologic literature//J Natl Cancer Inst. 1999. Vol.91. P.317-331.

9.Colditz G.A., Branch L.G., Lipnick R.J., Willett W.C., Rosner B., Posner B.M. Increased green and yellow vegetable intake and lowered cancer deaths in an elderly population//Am J Clin Nutr. 1985. Vol.41. P.32-36. 10. Kristenson M., Zieden B., Kucinskiene Z., Elinder L.S,. Bergdahl B., Elwing $B$., et al. Antioxidant state and mortality from coronary heart disease in Lithuanian and Swedish men: concomitant cross sectional study of men aged 50//BMJ. 1997. Vol.314. P.629-633. 